\title{
Impact of environmental toxin exposure on male fertility potential
}

\author{
Sarah C. Krzastek ${ }^{1,2,3}$, Jack Farhi ${ }^{1}$, Marisa Gray ${ }^{1}$, Ryan P. Smith ${ }^{1}$ \\ ${ }^{1}$ Department of Urology, University of Virginia, Charlottesville, VA, USA; ${ }^{2}$ Division of Urology, Virginia Commonwealth University, Richmond, \\ VA, USA; ${ }^{3}$ Division of Urology, Hunter Holmes McGuire VAMC, Richmond, VA, USA \\ Contributions: (I) Conception and design: All authors; (II) Administrative support: All authors; (III) Provision of study material or patients: None; \\ (IV) Collection and assembly of data: None; (V) Data analysis and interpretation: None; (VI) Manuscript writing: All authors; (VII) Final approval of \\ manuscript: All authors. \\ Correspondence to: Sarah C. Krzastek, MD. 1200 E Broad St, Box 980118, Richmond, VA 23298-0118, USA. Email: Sarah.Krzastek@vcuhealth.org.
}

\begin{abstract}
Idiopathic infertility is the most common individual diagnosis in male infertility, representing nearly $44 \%$ of cases. Research studies dating over the last half-century consistently demonstrate a decline in male fertility that is incompletely explained by obesity, known genetic causes, or diet and lifestyle changes alone. Human exposures have changed dramatically over the same time course as this fertility decline. Synthetic chemicals surround us. Some are benevolent; however, many are known to cause disruption of the hypothalamic-pituitary-gonadal axis and impair spermatogenesis. More than 80,000 chemicals are registered with the United States National Toxicology Program and nearly 2,000 new chemicals are introduced each year. Many of these are known toxins, such as phthalates, polycyclic aromatic hydrocarbons, aromatic amines, and organophosphate esters, and have been banned or significantly restricted by other countries as they carry known carcinogenic effects and are reproductively toxic. In the United States, many of these chemicals are still permissible in exposure levels known to cause reproductive harm. This contrasts to other chemical regulatory legislature, such as the European Union's REACH (Registration, Evaluation, Authorization and Restriction of Chemicals) regulations which are more comprehensive and restrictive. Quantification of these diverse exposures on an individual level has proven challenging, although forthcoming technologies may soon make this data available to consumers. Establishing causality and the proportion of idiopathic infertility attributable to environmental toxin exposures remains elusive, however, continued investigation, avoidance of exposure, and mitigation of risk is essential to our reproductive health. The aim of this review is to examine the literature linking changes in male fertility to some of the most common environmental exposures. Specifically, pesticides and herbicides such as dichlorodiphenyltrichloroethane (DDT), dibromochloropropane (DBCP), organophosphates and atrazine, endocrine disrupting compounds including plastic compounds phthalates and bisphenol A (BPA), heavy metals, natural gas/oil, non-ionizing radiation, air and noise pollution, lifestyle factors including diet, obesity, caffeine use, smoking, alcohol and drug use, as well as commonly prescribed medications will be discussed.
\end{abstract}

Keywords: Male infertility; environmental exposures; environmental toxins

Submitted Feb 29, 2020. Accepted for publication Oct 18, 2020.

doi: $10.21037 /$ tau-20-685

View this article at: http://dx.doi.org/10.21037/tau-20-685

\section{Introduction}

The previously debated male fertility decline is no longer controversial. Multiple corroborating studies have confirmed a fall in sperm counts and semen quality in men in the Western hemisphere over the last several decades
$(1,2)$. This decline cannot alone be attributed to obesity, illicit substance use, smoking rates, and alcohol abuse, but rather may in part be due to chronic environmental toxin exposures of the modern age. However, the studies elucidating the effect of various toxin exposures on 
spermatogenesis are problematic (3).

While acute exposure can cause dramatic changes to spermatogenesis, most environmental toxins impairing spermatogenesis are encountered through low-dose, chronic exposures. Animal studies investigating toxin impacts on fertility tend to demonstrate reduced spermatogenesis with exposures significantly higher than that found in the environment. In addition, most studies are retrospective population studies fraught with numerous confounders. These studies do not consider regional or ethnic differences which have been shown to cause variations in spermatogenesis. Even the male infertility population is discordant with the wider, general population (4). Despite the obstacles to studying the impact of chronic environmental toxin exposures on semen parameters, this review aims to summarize the recent literature on the effects of the more common environmental toxins on spermatogenesis.

\section{The impact of environmental exposures}

Numerous environmental factors have been implicated in the global decline in male fertility. Many compounds implicated are ubiquitous in our modern society and men may routinely encounter them during their daily activities. Alternatively, exposure may be following a larger scale environmental contamination such as that encountered after a nuclear accident or in situations requiring government Superfund cleanup. While data on long-term fertility outcomes following exposures to Superfund cleanup or nuclear accident sites are limited, data do note a link between prenatal exposure and preterm birth and congenital abnormalities $(5,6)$, suggesting that exposure to environmental toxins in these situations may negatively impact other fertility parameters. In addition, the Environmental Protection Agency (EPA) has acknowledged that certain compounds found at Superfund cleanup sites may have adverse fertility effects, that fertile men and women are at greater risk for negative effects, and suggest screening for exposure take fertility potential into account (7). Though exposure to high volumes of toxins in the setting of large-scale environmental contamination may affect male fertility, the following section is intended to define the most commonly-implicated toxins, and describe the mechanism by which they are thought to affect fertility, either through alterations in the hypothalamic-pituitarygonadal (HPG) axis, or through direct effects on sperm and other semen parameters. The effects of these compounds are summarized in Table 1.

\section{Pesticides/herbicides}

A pesticide is defined as "any substance or combination of substances used to prevent or eradicate unwanted insects including vectors of disease in human beings [or] animals, weeds, fungi, or [other organisms] in order to enhance food production and help production processing, storage, transport, or marketing of the food and agricultural commodities" (8). Numerous studies have linked pesticides to reduction in semen parameters. A 1977 study established an association between dibromochloropropane (DBCP) and a severe reduction in spermatogenesis among workers in the pesticide manufacturing industry (9). Dichlorodiphenyltrichloroethane (commonly known as DDT) is one of the pesticides most recognized for its association with potential adverse fertility outcomes. DDT and its metabolites including DBCP have demonstrated estrogenic effects in males by blocking androgen receptors (10-12). Since the initial study in 1977, DDT has been associated with numerous fertility concerns including decreased testosterone, testicular weight, number and percentage of motile spermatozoa in the epididymis, seminal vesicle weight, and increases in luteinizing hormone $(\mathrm{LH})$ and follicle stimulating hormone (FSH) $(13,14)$. Additionally, over 100 pesticides have been classified as endocrine disruptors with varying proposed mechanisms of action causing endocrine disruption and potential impacts on fertility measures (15).

Pesticides such as pyrethroids, organophosphates, phenoxyacetic acids, carbamates, organochlorines, and combinations of each have been investigated in the study of male fertility (16). Use of these agents across the United States agricultural industry is extensive, with organophosphates comprising $40-50 \%$ of all pesticides used. Organophosphate use is closely followed by use of atrazine, with more than 300 million pounds of organophosphates used in the US annually (17).

Organophosphate exposure has been associated with abnormal semen parameters including reductions in sperm counts, motility, viability, and density, and increased DNA damage and abnormal morphology (8). Additionally, organophosphates have been associated with macroscopic testicular changes including reduced testicular volume (8). Numerous other studies demonstrate that organophosphates alter serum reproductive hormones and may be associated with decreased total testosterone 
Table 1 Common environmental exposures, hypothesized mechanisms of action and effects on fertility

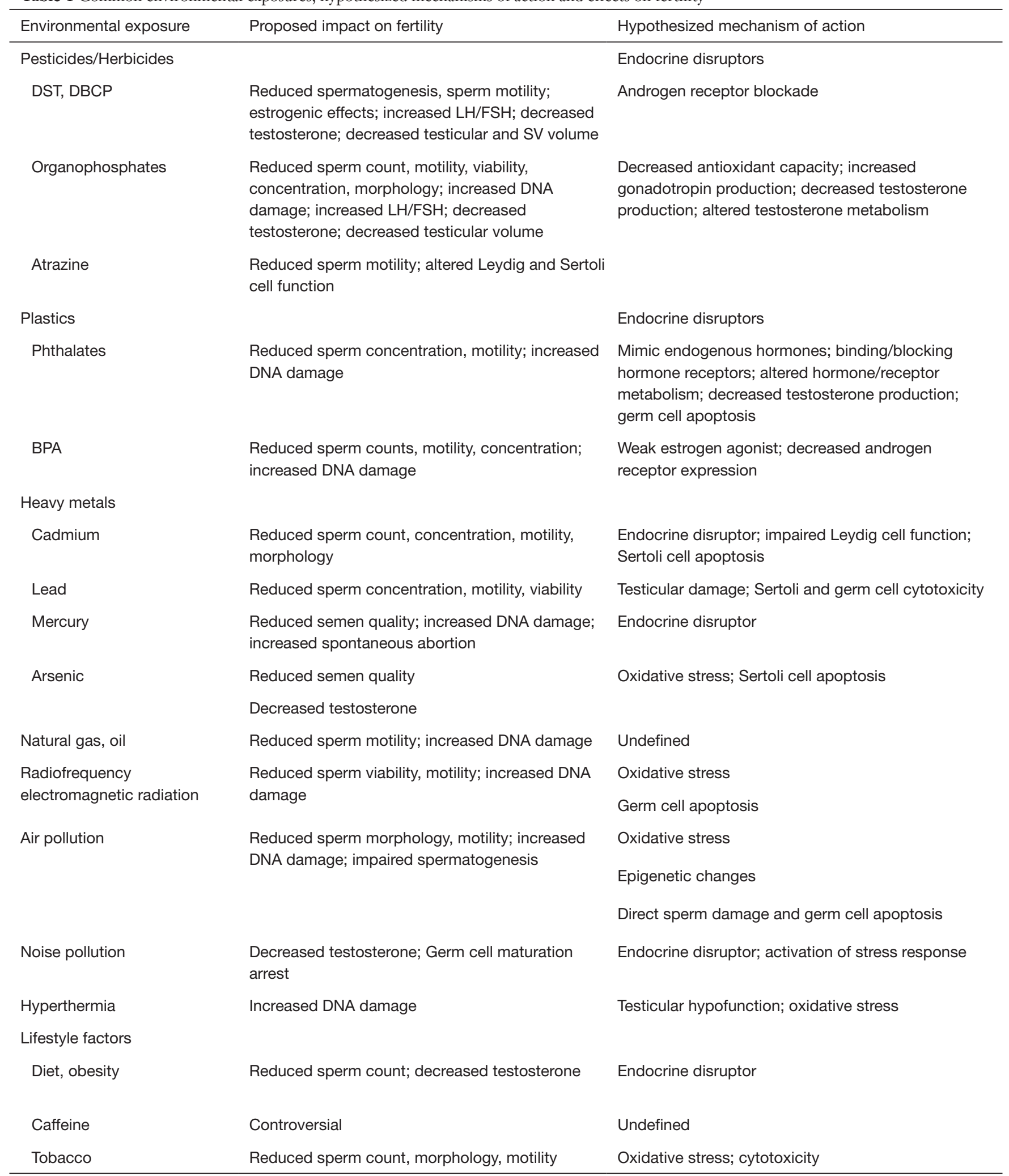

Table 1 (continued) 
Table 1 (continued)

\begin{tabular}{|c|c|c|}
\hline Environmental exposure & Proposed impact on fertility & Hypothesized mechanism of action \\
\hline Anabolic-androgenic steroids & Impaired spermatogenesis & Suppression of gonadotropins \\
\hline
\end{tabular}

$\mathrm{LH}$, luteinizing hormone; FSH, follicle stimulating hormone.

and increased LH and FSH levels (18-20). However, organophosphate effects on the hypothalamic-pituitarygonadotropin (HPG) axis remain controversial. A recent study of Iranian farmers suggested an increased testosterone level with low LH and FSH (21). It has been hypothesized that organophosphates may impact fertility either by directly affecting spermatogenesis through decreased antioxidant capacity, impairment of testicular production of testosterone, alterations of testosterone metabolism systemically, or by affecting production of gonadotropins centrally (21).

Atrazine, the second most commonly utilized organophosphate in the United States, has also been associated with a decline in semen parameters in certain agricultural communities (22). In animal studies, atrazine injected intraperitoneally for 60 days caused a $55 \%$ reduction in sperm motility in a non-dose dependent fashion and was associated with testicular histologic changes including irregular size and shape of Leydig cells and vacuolization of Sertoli cells (23).

\section{Plastic compounds and other endocrine disruptors}

Endocrine disrupting compounds (EDCs) mimic or block the effects of naturally circulating hormones by binding to their receptors (24). EDC's and other potentially reproductively toxic compounds can be found in a variety of everyday products such as shampoos, clothing, toothpastes, soaps, textiles, carpets, linens, toys, deodorant, cosmetics and in implantable materials such as permanent makeup and body ink (25-27). EDC's have also been identified in agricultural and food products as well as air and water contaminants. While concern regarding microplastic ingestion was increasingly reported in 2019, the bioavailability of EDC's through dermal exposure may be underestimated.

Tabb and colleagues elucidated several mechanisms of action for EDCs including agonistic or antagonistic action on estrogen, androgen, and thyroid hormone receptors. Additional mechanisms of action include interference with transcriptional activity of nuclear receptors, effects on DNA methylation status and lipid metabolism, disruption of testicular gap junction communication, or interference with the synthesis or transport of hormones (24). The impact of EDCs on male hormonal pathways, specifically the reproductive system, is a topic of concern regarding male fertility. Below, we will address several common EDCs present in plastic materials specifically.

\section{Phthalates}

Phthalate esters are incorporated into plastic products to increase flexibility, transparency, and durability. These compounds are ubiquitous in our modern environment, found in everything from adhesives, flooring, and wall coverings to fragrances, cosmetics, and household and personal care products. Phthalates can even be found in some foods and water sources. Phthalates can enter the human body through the skin, ingestion, or inhalation, and compounds or their metabolites can be detected in semen $(28,29)$. Phthalates have been reported to negatively impact semen parameters (30). Children have been found to have higher exposure levels to phthalates than adults. Exposure has declined over the past decade due to stricter industry regulations on phthalates specifically, prompting the use of alternative plasticizers (28).

How phthalates impact fertility remains unclear, but these compounds are thought to disrupt the endocrine system by mimicking endogenous hormones, binding or blocking endogenous hormone receptors, and interfering with receptor metabolism $(28,31)$. Additional proposed 
mechanisms of action include decreased testosterone synthesis of Leydig cells, expression of steroidogenic proteins or growth factor, or induction of germ cell apoptosis (32-35). A meta-analysis by Cai and colleagues in 2015 intended to summarize evidence for associations between phthalate exposures and human semen quality (36). Their meta-analysis included 14 studies that explored phthalates and their metabolite levels in urine and blood and the link to semen quality in humans. They found that urinary monobutyl phthalate (MBP) and monobenzyl phthalate $(\mathrm{MBzP})$ were associated with reduced sperm concentration, MBP and mono(2-ethylhexyl) phthalate (MEHP) were associated with decreased motility and motion semen parameters, and MBzP and MEP were associated with increased sperm DNA damage. Overall, this meta-analysis strengthened evidence that specific phthalates or their metabolite levels appear to affect semen quality.

\section{Bisphenol A (BPA)}

BPA is another highly prevalent chemical in society, primarily found in plastic products and epoxy resins. In vitro studies showed unconjugated BPA binds to estrogen receptors, providing weak estrogen activity (37). There have been numerous studies in mice and rats which show decreased sperm counts (38-42), impaired sperm motility $(40,41,43)$, and increased sperm DNA damage $(43-47)$ as a result of BPA exposure. Studies suggest that decreased androgen receptor expression contributes to spermatogenesis failure in rats (42).

Studies on the effect of BPA on human reproductive health have produced incongruent results. The largest review of current literature was performed by MínguezAlarcón and colleagues in 2016 (48). Their group reviewed a total of 11 studies regarding BPA and fertility in humans which were further broken down into subcategories. Five studies evaluated the relationship between BPA and semen quality. One study found that increasing urinary BPA was significantly associated with decreased sperm concentration, decreased total sperm count, decreased sperm vitality, and decreased sperm motility (49). This is the only prospective study to date. However, the remaining four studies reported no associations with various parameters, aside from an association of increased BPA with decreased progressive sperm motility $(50,51)$. Methodologic differences could explain some of the discrepancies between studies; however contradictory results were found even among populations with comparable urinary BPA concentrations. Five studies explored the relationship between male BPA exposure and reproductive hormones including testosterone, LH, FSH, inhibin B, estrogen, and testosterone. Each study found significant associations with at least one reproductive hormone; however, no relationship was consistently observed across all the studies. Finally, the three studies which examined male urinary BPA levels and reproductive outcomes found no association with fertilization, embryo quality, implantation, live births, or time to pregnancy $(52,53)$. While animal models suggest significant negative impacts on fertility outcomes as a result of BPA exposure, the overall evidence supporting an association between BPA exposure and adverse male reproductive health outcomes in humans remains limited and inconclusive.

\section{Heavy metals}

Heavy metals cause toxicity by impacting the HPG axis, testicular function, spermatogenesis and sperm processing (54). Of greatest concern are the heavy metals cadmium, lead, mercury, and arsenic.

Cadmium is released into the environment during various industrial process including battery manufacturing and metal smelting, and can be found in tobacco smoke $(55,56)$. It is a known reproductive toxin that is thought to disrupt the HPG axis, directly impair Leydig cell function, and induce cellular apoptosis and cytoplasmic damage within Sertoli cells through disruption of tight junctions and alteration of cell signaling pathways. Cadmium is thought to reduce sperm counts and concentration, and increase sperm DNA damage (56).

Lead exposure also poses a substantial reproductive and public health threat. Even with low level exposure in smelting industry workers, lead has been associated with decreased semen concentration, motility and viability (57). Lead likely induces damage at the testicular level, and secondarily alters the HPG axis. Lead is also cytotoxic to Sertoli and germ cells (58). Furthermore, in a study of Belgian smelters, excessive lead resulted in inappropriate inhibin B overproduction which is a marker of Sertoli cell damage (59).

Human exposure to mercury primarily comes through consumption of seafood, but can also result from exposure to certain dental compounds, batteries, fluorescent light bulbs, and some skin-lightening creams (60). A recent systematic review by Henriques and colleagues found that higher levels of mercury were associated with male 
subfertility, higher rates of spontaneous abortion, decreased semen quality, and higher levels of DNA damage (60). The authors acknowledge, however, that studies on the topic are heterogeneous and definitive conclusions could not be drawn. Though the exact mechanism by which mercury induces male subfertility remains somewhat unclear, it is hypothesized that this metal acts as an endocrine disruptor.

Arsenic has also been a metal of interest thought to impact fertility. Arsenic is thought to act directly on the testis by induction of oxidative stress in the micro-testicular environment leading to impaired semen quality, decreased serum testosterone in mice, and activation of cell signaling leading to apoptosis in Sertoli cells (61-63). Arsenic lowers $3 \beta$-hydroxysteroid dehydrogenase which plays an important role in steroidogenesis. This may be reversible with ascorbic acid and other antioxidants that may be protective against the reactive oxygen species (ROS) (64-66). Additional studies are needed to determine clinically significant levels of heavy metal exposures and the mechanisms underlying subsequent fertility impairments.

\section{Natural gas and oil}

With the ongoing dependence on natural gas and oil, the potential for exposure to these compounds persists through extraction, processing, and manufacturing byproducts. A systematic review by Balise and colleagues in 2016 examined seven studies assessing semen quality, fertility, and birth outcomes resulting from paternal exposure to oil and gas industry activities (67). Studies reported mixed results regarding the impact of exposure on sperm concentration or viability. There appeared to be a stronger association between exposure and decreased sperm motility. In limited studies, sperm morphology did not appear to be affected. One study was identified which investigated $e x$ vivo experimental exposure to oil and gas-related chemicals and sperm DNA damage. The authors found a decrease in intact double-stranded DNA and an increase in denatured single-stranded DNA after exposure to two benzene metabolites commonly found in petroleum industries $(\mathrm{P}<0.001)$. However, this group found that many studies were underpowered to detect a statistically significant impact, and, as with other toxins, whether changes in semen parameters translates into poorer fertility outcomes remains to be determined.

\section{Radiation}

Ionizing radiation in the form of medical diagnostic imaging, radiotherapy, or even through nuclear accidents is well known to have a negative impact on spermatogenesis via induction of oxidative stress and DNA damage with subsequent death of spermatocytes and spermatogonia (68-70). While exposure to ionizing radiation in doses as low as 30 Gy may cause damage to genes during spermatogenesis, genetic instability may persist following exposure and DNA damage may be transmitted to future offspring (71).

The risk of exposure to non-ionizing radiation in the form of radiofrequency electromagnetic radiation (RFEMR) is less well studied. As modern society becomes increasingly dependent on technology in parallel with declining male fertility, the question arises as to whether there is an association between radiation in our environment or emitted by our devices and male infertility. Mobile phones emit RF-EMR at a frequency of $800-2,200 \mathrm{MHz}$. RF-EMR emitted by mobile phones is thought to result in rapid heating and induction of ROS and DNA damage and in animal models RF-EMR has been associated with sperm cell death and histologic changes within the testis (72). A meta-analysis by Adams et al. in 2014 examined 10 studies evaluating the effects of mobile phone exposure on sperm quality (72). This group found that mobile phone exposure was associated with decreases in sperm motility and viability.

Laptop computers also emit RF-EMR at a frequency of $300 \mathrm{~Hz}-10 \mathrm{MHz}$, with wireless signals emitting at $2.4 \mathrm{GHz}$. Laptops connected to wireless internet have been associated with decreased sperm motility and increased DNA fragmentation, thought to be linked both to thermal effects and exposure of the testes to RF-EMR (73-75). Avendaño et al. subjected motile human sperm to incubation under a laptop computer actively working and connected to wireless internet for four hours (73). Environmental temperatures were controlled at $25^{\circ} \mathrm{C}$ for both specimens subjected to laptop RF-EMR and control specimens. Following exposure, DNA fragmentation, sperm viability and motility were assessed. Exposure did not affect overall sperm viability, but exposure to laptop RF-EMR did result in significant reductions in sperm motility [progressive sperm motility $68.7 \% \pm 8.8 \%$ (treatment) vs. $80.9 \% \pm 7.5 \%$ (control), $\mathrm{P}<0.01$; immotile sperm $24.5 \% \pm 7.6 \%$ (treatment) vs. $13.6 \% \pm 5.6 \%$ (control), $\mathrm{P}<0.01]$ and increases in DNA 
fragmentation assessed on TUNEL assay $[8.6 \% \pm 6.6 \%$ (treatment) vs. $3.3 \% \pm 6.0 \%$ (control), $\mathrm{P}<0.01]$. Other studies have also supported a negative impact on sperm motility following exposure to laptop activity with $3 \mathrm{G}$ wireless internet transmission (76).

Though animal studies and in vitro studies on human sperm suggest a strong association between thermal heat and RF-EMR and impairments in sperm motility and increased DNA fragmentation, further study needs to be conducted to fully establish their overall impact on male fertility.

\section{Air pollution}

Air pollution consists of particulate matter $\left(\mathrm{PM}_{2.5}\right.$, particulate diameter $<2.5 \mu \mathrm{M} ; \mathrm{PM}_{10}$, particulate diameter $<10 \mu \mathrm{m})$ and gaseous pollutants such as ozone $\left(\mathrm{O}_{3}\right)$, nitrogen dioxide $\left(\mathrm{NO}_{2}\right)$, sulfur dioxide $\left(\mathrm{SO}_{2}\right)$, and carbon monoxide (CO). Taken together, air pollution has been identified by the World Health Organization (WHO) as the world's largest environmental-health risk, and exposure of fine particulate matter and heavy metals through air pollution has been associated with development and progression of cardiovascular disease, lung cancer, testicular cancer, epigenetic alterations and germ cell genetic mutations (77-80). Additionally, even exposures to levels below the current U.S. regulatory standards may have adverse effects on health (77). In terms of the impact of air pollution on male fertility, exposure to pollutants has been associated with increased sperm DNA fragmentation, chromosomal abnormalities, impaired spermatogenesis, abnormal sperm morphology and decreased sperm motility $(79,81)$. These changes are thought to be due to reactive oxygen species, epigenetic changes, and cell apoptosis (79).

A systematic review by Lafuente $e t a l$. in 2016 examined the link between air pollution and sperm quality parameters including DNA fragmentation, sperm motility, count and morphology (82). Included studies were found to be highly heterogeneous and direct comparison was difficult, with only 3 of 6 studies showing a link between air pollution and DNA fragmentation, only 6 of 12 studies showing an association with impaired sperm motility, and 6 of 13 articles reporting an association between air pollution and decreased sperm counts. Seven of 10 articles reported a link between air pollution and abnormal sperm morphology. The authors acknowledged the questionable clinical significance of this finding, as sperm morphology has not been shown to definitively impact fertility potential. A similar systematic review and meta-analysis by Deng and colleagues in 2016 showed a large degree of heterogeneity in published articles, and conflicting results regarding the link between exposure to air pollution and impairments in sperm motility and morphology, with a trend towards an association (83).

In attempt to control for heterogeneity in reported air pollutants studied, Zhang et al. analyzed semen specimens collected in Beijing, China, during a period of time with no air pollution control from 2015-2017 and compared analyses to samples collected during a period of pollution control from 2017-2018 (84). Six pollutants were measured, including $\mathrm{PM}_{2.5}, \mathrm{PM}_{10}, \mathrm{O}_{3}, \mathrm{NO}_{2}, \mathrm{SO}_{2}$, and CO. Across the total study time period, only exposure to $\mathrm{O}_{3}$ was associated with decreased sperm concentration. $\mathrm{O}_{3}$ exposure is hypothesized to impact semen quality by generating excessive ROS and by directly damaging sperm DNA integrity. Work is ongoing to generate high-quality evidence to support a link between air pollution and impairments in semen quality (85).

\section{Noise pollution}

An additional source of environmental pollution is increased ambient sound, commonly known as "noise pollution." In addition to an impact on mental health and sleep quality, animal models have demonstrated that noise stress may be associated with alterations in testicular histology and decreased serum testosterone levels with resultant germ cell maturation arrest (86). Though little work has been done to evaluate the impacts of noise pollution on male fertility in human subjects, the results in animal models may translate to results in the human population. A study by Min and Min in 2017 found that after controlling for age, residential area, and other lifestyle factors, while small 1 decibel increases in daytime or nighttime noise was not associated with increased risk of infertility, men exposed to increased noise levels at the second to fourth quartile had significantly increased odds of infertility $(\mathrm{P}<0.05)(87)$. It was hypothesized that increased risk for infertility in men exposed to high levels of noise pollution may be due to activation of stress responses and alterations in the hypothalamic-pituitary-gonadal (HPG) axis with ultimate suppression of testosterone $(87,88)$.

\section{Hyperthermia}

Testicular temperatures are lower than core temperatures due to two thermal regulatory mechanisms. First, the 
scrotal rugae provide a variable surface area controlled by the underlying Dartos fascia. This allows for heat escape through numerous apocrine glands. Second, the pampiniform plexus creates counter-current heat exchange between arterial and venous blood. Hyperthermia impairs spermatogenesis and testicular function and transient hyperthermia results in a decrease in sperm concentration and motility $(89,90)$. Even mild transient increases in scrotal temperature by 2 degrees Celsius impair sperm chromatin integrity (91). However, continuous rather than transient hyperthermia has been associated with increased sperm cell DNA damage and apoptosis (92). Multiple environmental factors have been associated with scrotal hyperthermia including saunas, clothing, sleeping position, laptop use, driving for long periods, and welding (75,93-97). Regular use of hot tubs, jacuzzis and saunas have been show to result in transient impairments in semen parameters due to elevations in testicular temperatures (98). Many men may not recognize the potential negative impact of increased scrotal temperatures on fertility, and men presenting for fertility evaluation should be counseled about the potential risks of chronic scrotal hyperthermia.

\section{Lifestyle}

\section{Diet and obesity}

Diet quality has significantly declined in Western countries over the past 50 years and numerous studies suggest that adherence to a healthy diet is associated with better semen parameters (99). Additionally, obesity is associated with decreased testosterone and reduced semen parameters (100). In one study of 501 couples attempting to conceive within 2 years, obesity and waist circumference had a negative linear relationship with ejaculate volume and total sperm count, though no statistical relationship was found between motility, sperm concentration, morphology, or DNA fragmentation index (101). If obesity is associated with impaired semen parameters, it would be intuitive that weight loss surgery may be associated with improvements. Evidence to support this remains unclear, as studies have demonstrated that while bariatric surgery increases testosterone, LH, FSH, and SHBG, thus leading to a decrease in estradiol and prolactin, semen parameters remain unchanged (102). Moderate exercise, however, does appear to have a neutral or positive impact on semen parameters, whereas intense exercise may negatively affect sperm concentration, motility and morphology (103). A recent study by Nassan et al. demonstrated that Danish men eating a "Western" diet of processed foods had poorer sperm counts compared to those eating a vegetarian, "opensandwich," or prudent diet. Those with a prudent diet characterized by fish, chicken, vegetables, fruit and water had the highest sperm counts (99).

\section{Caffeine}

Caffeine's effect on spermatogenesis is controversial. Ricci and colleagues attempted to perform a systematic review to assess the impact of caffeine intake on male fertility (104). Though some evidence suggested a link between caffeine intake and decreased semen volume, sperm count and concentration, and increased DNA abnormalities, definitive conclusions could not be drawn. The only meta-analysis in the literature reviews two articles with coffee consumption which concluded that the effects of coffee on semen parameters were statistically insignificant (105). However, a recent study associated a paternal intake of $272 \mathrm{mg} / \mathrm{d}$ caffeine with reduced live birth rates in intracytoplasmic sperm injection (ICSI) cycles (106). The impact of caffeine consumption on male fertility remains controversial.

\section{Smoking}

Tobacco is considered a known cause of male factor infertility, with cigarette smoking linked to decreases in semen volume, sperm count, and sperm motility in a dosedependent and reversible manner, as well as to impaired assisted reproduction technique (ART) outcomes (107). A recent meta-analysis evaluated data from 16 studies of men with male factor infertility and determined that sperm count and morphology were reduced; while motility and semen $\mathrm{pH}$ were preserved (108). Another recent metaanalysis containing over 5,000 men with male factor infertility determined that cigarette smoking was associated with reduced count and motility (109). Kubincová et al. demonstrated that polycyclic aromatic hydrocarbons, well-recognized endocrine disrupting chemicals and reproductive toxicants in cigarette smoke, can induce endocrine-disrupting effects in males through dysregulation of testicular gap junction intercellular communication and subsequent degradation of testicular gap junction protein connexin 43 in Leydig cells (26). In addition to toxins found in cigarette smoke, nicotine is also thought to independently have a negative impact on semen parameters (107).

While cigarette use is associated with reduced semen parameters, the data on electronic cigarette use is limited. Electronic cigarettes have been marketed as less harmful than conventional cigarettes, with conventional cigarette 
smoke containing a carcinogenic and toxic mixture of 5,000 chemicals (110). However, given the negative link between nicotine and semen parameters, electronic cigarettes still pose a theoretical risk to male fertility. A recent study demonstrated a reduction in sperm count in the cauda of the rat epididymis when exposed to electronic cigarette refill with and without nicotine (111). This study suggests that electronic cigarettes may have harmful impacts on the reproductive system. Further human observational studies need to be performed to determine the ramifications of electronic cigarette use on human semen parameters.

\section{Alcohol}

According to the 2018 National Survey on Drug Use and Health, over the preceding month, $55 \%$ of adults in the United States consumed alcohol and 26\% of adults engaged in binge drinking (112). A recent study compared semen parameters, LH, FSH, estrogen, and testosterone levels of 66 alcoholics free from smoking and drug abuse compared to 30 nonsmoking nonalcoholic men as controls (113). Chronic alcoholism reduced testosterone hormone levels causing a compensatory LH increase. All sperm parameters were significantly negatively affected by chronic alcohol abuse. FSH was increased in alcoholics due to loss of seminiferous tubule function. Previous other studies have shown similar findings of hypogonadism and decreased spermatogenesis (114-118). Currently, patients presenting for a fertility evaluation are counseled to minimize alcohol consumption, and to particularly avoid binge drinking.

\section{Recreational drugs}

Marijuana is the most frequently used illicit drug. Sixteen percent of adults in the United States have used marijuana in the past year (112). Few studies have examined the direct effect of marijuana on male infertility, but marijuana use has been associated with dysregulation of HPG axis causing hypogonadism with reduction in LH without effect on FSH (119). Marijuana also directly affects semen parameters and sperm function by acting on the cannabinoid and vanilloid receptors. Activation of the cannabinoid 1 and 2 receptors decrease motility and viability of spermatozoa $(120,121)$. Activation of cannabinoids 1 receptors also inhibits the capacitation-inducted acrosomal reaction during fertilization (122). With the decriminalization and legalization of marijuana, more studies are needed to fully distinguish differences in acute and chronic marijuana use, determine doses associated with clinically significant changes, and to further determine the underlying mechanism of marijuana-associated subfertility.

Anabolic-androgenic steroids (AAS) are also frequently abused in the recreational setting, with an overall lifetime prevalence of AAS use globally of $6.4 \%$ amongst males. Prevalence of AAS use is highest among recreational sportsmen, body builders, and athletes, particularly among adolescents (123). Numerous studies have elucidated AAS effects on endogenous androgen production and spermatogenesis. AAS use is known to result in oligospermia and even azoospermia by inhibiting gonadotropin and intrinsic testosterone production through negative feedback on the HPG axis. Suppression of LH and FSH results in arrest of Leydig and Sertoli cell function, with ultimate inhibition of testicular function and decreased spermatogenesis (124). In body builders, AAS abuse increases the rate of oligoteratospermia compared to controls (125). Although hypogonadotropic hypogonadism with AAS use may be transient, recovery of normal spermatogenesis may be prolonged (126).

\section{Medications}

Numerous prescribed and over-the-counter medications have been associated with impairments in male fertility, and a complete overview of all medications implicated is beyond the scope of this review. Pharmaceuticals may disrupt the HPG axis, affect cortisol levels, alter the production of sex hormone binding globulin, prolactin or thyroid hormone levels. Medications may also directly affect testicular tissue through disruption of Leydig or Sertoli cell function, impair epididymal sperm transit or ejaculation, and have even been implicated in fertilization (127). Some of the strongest existing evidence concerns selective serotonin reuptake inhibitor anti-depressants, alpha blockers, calcium channel blockers, and antiretrovirals $(128,129)$.

Opioid use has also been associated with male subfertility, which is of particular concern given the recent opioid crisis in the United States. Multiple studies have demonstrated that long term use of opioids suppresses hypothalamic secretion of $\mathrm{GnRH}$ and the function of the HPG axis $(130,131)$. Even tramadol has been associated with decreased sperm motility, primary hypogonadism, and hyperprolactinemia (132). In addition to disrupting the HPG axis, opioid use has been associated with decreased sperm motility and concentration, thought to be related to a direct impact on sperm function as evidence by the presence of delta-, kappa-, and mu-opioid receptors on the membranes of spermatozoa $(133,134)$. 


\section{Does the timing of environmental exposure affect fertility outcomes?}

Based on the mechanism by which environmental toxins impact male fertility, particularly through the theorized generation of ROS, it would be intuitive that fetal exposures may lead to longer lasting negative impacts on overall development and future spermatogenesis than would exposure during adulthood. In fact, studies suggest that negative impacts on spermatogenesis may be reversible in adults following removal of exposure to the toxin $(107,135,136)$. Though outcomes following early exposure to toxins such as phthalates and other endocrine disruptors remain controversial, most studies do show that early exposure is linked to negative developmental outcomes (28). Specifically, prenatal exposure to cigarette smoking has been associated with decreased sperm concentration and testicular size in adults (107).

The risk of congenital gonadal malformations as may be seen with testicular dysgenesis syndrome (TDS) appears to be associated with fetal exposure to certain medications, tobacco and alcohol, and other endocrine disruptors. Some evidence suggests that prenatal effects may be irreversible (136). TDS has been proposed as a congenital condition resulting from disrupted testicular development in utero which may lead to a combination of cryptorchidism, hypospadias, and testicular cancer (136). It is interesting to note that semen parameters have been declining seemingly in correlation with increasing rates of TDS, raising the question as to whether the same environmental exposure that may be linked to impairments in male fertility may also predispose infants to development of congenital gonadal abnormalities. While prospective studies comparing the effects of prenatal to postnatal exposures would be impossible, clearly much more research needs to be done to elucidate the long-term effects of early exposures to environmental toxins on reproductive health.

\section{Prevention and treatment of damage induced by environmental toxins}

The most effective means of minimizing the negative effects of environmental toxins is exposure avoidance or reduction. Given the broad number of potential environmental toxins, it would be extremely difficult for an individual to eliminate all possible exposures. Interestingly, proprietary silicone wristbands have been shown to detect a number of harmful compounds including polycyclic aromatic hydrocarbons and may provide consumers with previously unavailable data on personalized exposure profiles $(137,138)$. A crosssectional study conducted in 2018 showed that while in utero exposure to maternal tobacco use was associated with decreased semen quality, decreases in maternal tobacco use over time did not correspond to improvements in semen quality. This suggests additional etiologies for persistent impairments in semen quality over time (139).

Some studies suggest that impairments in spermatogenesis may be reversible with removal of exposure to the offending agent, for example as with weight loss, alcohol, tobacco or use of certain medications $(4,100,135)$. The ability to reverse the damage may depend on the timing and type of exposure. While eliminating an environmental toxin may help improve semen parameters in men presenting with subfertility, improving semen parameters in men who were exposed to toxic agents in utero may prove more difficult. Small studies suggest that smoking cessation may improve semen parameters (140). Similarly, certain chemotherapeutic agents are more gonadotoxic than others, and adverse impacts on spermatogenesis may be mitigated by using alternative agents or lower doses as able (135). Animal models have also suggested that the addition of GnRH analogues during chemotherapy may preserve the potential of spermatogonia to differentiate following treatment (135). This has not borne out in human studies.

As it is difficult to remove men from toxins ubiquitous throughout our environment, much interest has been placed on identifying treatment options to protect men from, or reverse, the negative effects of these agents. As discussed above, scrotal hyperthermia may be an underlying mechanism for the negative fertility outcomes from certain environmental exposures. Scrotal cooling has been investigated as a way to improve semen parameters in the setting of hyperthermia induced by varicoceles and has been shown to improve semen parameters including sperm concentration, motility and morphology $(141,142)$. More recently, a systematic review by Nikolopoulos and colleagues in 2013 reviewed the evidence associating scrotal cooling with changes in semen parameters (143). The authors noted that most studies on the topic were small observational studies with no randomized controlled trials, so no firm conclusions could be drawn, but all studies included did show a trend towards improvement in sperm count, as well as six of eight studies showing improvements in sperm motility and/or morphology.

ROS may be another etiology of reason for impaired 
semen parameters following environmental exposures. Therefore, it is logical to hypothesize that administration of antioxidants may protect against or blunt the effects of these toxins. Antioxidants including Zinc, Vitamins E and C, Selenium, Coenzyme Q10, Ferulic acid, and even melatonin have been shown to have protective effects on spermatogenesis in animal models and reduce semen ROS and DNA fragmentation in human studies (144-146). There is no definitive evidence to support the use of antioxidant supplementation in subfertile men to improve pregnancy and live birth rates due to a lack of high quality studies (147). However, given their low cost and few side effects, antioxidants and multivitamins are frequently recommended to men presenting with subfertility $(148,149)$.

The literature is fraught with limited high-quality evidence to support any one therapy for treatment of impaired fertility linked to environmental exposures. Due to the diversity of exposures to environmental toxins which may have a negative impact on fertility, the need for change on a global scale becomes more apparent. It may prove futile to try to limit exposures until a paradigm shift takes place to reduce the release of these toxins and subsequent human exposures. Until a stronger link can be defined, men presenting with fertility concerns should be counseled to minimize environmental exposures and may consider regular consumption of dietary antioxidants or use of a daily multivitamin.

\section{Conclusions}

Two things are clear-we are continuously exposed to environmental toxins in our daily lives and male fertility is declining. Though there is some evidence to suggest a link between these environmental exposures and male fertility, irrefutable evidence linking these everyday toxins to the known male fertility decline is elusive. This is not due to a lack of evidence of these agents to cause reproductive harm but is attributable to the complex longitudinal studies required to establish causality and the ethical concerns of conducting prospective clinical trials involving human exposures. Additionally, while these toxins may result in impairments in semen parameters, it remains to be determined if these changes translate into diminished pregnancy and live birth rates. Until more is known about how our environment affects male fertility, exposure to these compounds should be minimized and avoidance practiced where feasible. The reproductive health of future generations will likely hinge on several factors, including the empowerment of governmental organizations to establish concentration limits, abolish the use of some substances and increasingly regulate the use of agents with potential reproductive harm. This requires a proactive and precautionary approach as opposed to a reactionary one, waiting until the harm is manifest, which is the current regulatory paradigm. New technologies are arising which will give consumers the ability to quantify their exposures and in turn, hopes of increased public recognition of the potential for harm and the advocacy to evoke change on a larger scale.

\section{Acknowledgments}

Funding: None.

\section{Footnote}

Peer Review File: Available at http://dx.doi.org/10.21037/ tau-20-685

Conflicts of Interest: All authors have completed the ICMJE uniform disclosure form (available at http://dx.doi. org/10.21037/tau-20-685). RPS serves as an unpaid editorial board member of Translational Andrology and Urology from Aug 2020 - Jul 2022. The other authors have no conflicts of interest to declare.

Ethical Statement: The authors are accountable for all aspects of the work in ensuring that questions related to the accuracy or integrity of any part of the work are appropriately investigated and resolved.

Open Access Statement: This is an Open Access article distributed in accordance with the Creative Commons Attribution-NonCommercial-NoDerivs 4.0 International License (CC BY-NC-ND 4.0), which permits the noncommercial replication and distribution of the article with the strict proviso that no changes or edits are made and the original work is properly cited (including links to both the formal publication through the relevant DOI and the license). See: https://creativecommons.org/licenses/by-nc-nd/4.0/.

\section{References}

1. Sengupta P, Borges E, Dutta S, et al. Decline in sperm count in European men during the past 50 years. Hum Exp Toxicol 2018;37:247-55. 
2. Levine H, Jørgensen N, Martino-Andrade A, et al. Temporal trends in sperm count: a systematic review and meta-regression analysis. Hum Reprod Update 2017;23:646-59.

3. Mima M, Greenwald D, Ohlander S. Environmental Toxins and Male Fertility. Curr Urol Rep 2018;19:50.

4. Gabrielsen JS, Tanrikut C. Chronic exposures and male fertility: the impacts of environment, diet, and drug use on spermatogenesis. Andrology 2016;4:648-61.

5. Currie J, Greenstone M, Moretti E. Superfund cleanups and infant health. Am Econ Rev 2011;101:435-41.

6. Grant fuels study of Superfund impact on preterm births [Internet]. Baylor College of Medicine. [cited 2020 May 12]. Available online: https://www.bcm.edu/news/ pediatrics/superfund-grant-study-impact-on-pretermbirth

7. Risk Assessment Guidance for Superfund Volume I Human Health Evaluation Manual (Part A) Interim Final [Internet]. Washington, D.C 20450: Office of Emergnecy and Remedial Response; U.S. Environmental Protection Agency; 1989 [cited 2020 May 12]. Available online: epa. gov/sites/production/files/2015-09/documents/rags_a.pdf

8. Mehrpour O, Karrari P, Zamani N, et al. Occupational exposure to pesticides and consequences on male semen and fertility: a review. Toxicol Lett 2014;230:146-56.

9. Teitelbaum DT. The toxicology of 1,2-dibromo-3chloropropane (DBCP): a brief review. Int J Occup Environ Health 1999;5:122-6.

10. Whorton D, Milby TH, Krauss RM, et al. Testicular function in DBCB exposed pesticide workers. J Occup Med 1979;21:161-6.

11. Kelce WR, Stone CR, Laws SC, et al. Persistent DDT metabolite p,p'-DDE is a potent androgen receptor antagonist. Nature 1995;375:581-5.

12. Bernard L, Martinat N, Lécureuil C, et al. Dichlorodiphenyltrichloroethane impairs folliclestimulating hormone receptor-mediated signaling in rat Sertoli cells. Reprod Toxicol 2007;23:158-64.

13. Martin SA, Harlow SD, Sowers MF, et al. DDT metabolite and androgens in African-American farmers. Epidemiology 2002;13:454-8.

14. Ben Rhouma K, Tébourbi O, Krichah R, et al. Reproductive toxicity of DDT in adult male rats. Hum Exp Toxicol 2001;20:393-7.

15. Mnif W, Hassine AIH, Bouaziz A, et al. Effect of endocrine disruptor pesticides: a review. Int J Environ Res Public Health 2011;8:2265-303.

16. Perry MJ. Effects of environmental and occupational pesticide exposure on human sperm: a systematic review. Hum Reprod Update 2008;14:233-42.

17. Atwood D, Paisley-Jones C. Pesticides Industry Sales and Usage [Internet] 2017. Available online: https://www.epa. gov/sites/production/files/2017-01/documents/pesticidesindustry-sales-usage-2016_0.pdf.

18. Melgarejo M, Mendiola J, Koch HM, et al. Associations between urinary organophosphate pesticide metabolite levels and reproductive parameters in men from an infertility clinic. Environ Res 2015;137:292-8.

19. Miranda-Contreras L, Gómez-Pérez R, Rojas G, et al. Occupational exposure to organophosphate and carbamate pesticides affects sperm chromatin integrity and reproductive hormone levels among Venezuelan farm workers. J Occup Health 2013;55:195-203.

20. Panuwet P, Ladva C, Barr DB,et al. Investigation of associations between exposures to pesticides and testosterone levels in Thai farmers. Arch Environ Occup Health 2018;73:205-18.

21. Ghafouri-Khosrowshahi A, Ranjbar A, Mousavi L,et al. Chronic exposure to organophosphate pesticides as an important challenge in promoting reproductive health: A comparative study. J Educ Health Promot 2019;8:149.

22. Swan SH. Semen quality in fertile US men in relation to geographical area and pesticide exposure. Int J Androl 2006;29:62-8; discussion 105-8.

23. Kniewald J, Jakomini M, Tomljenovi A, et al. Disorders of male rat reproductive tract under the influence of atrazine. J Appl Toxicol 2000;20:61-8.

24. Tabb MM, Blumberg B. New modes of action for endocrine-disrupting chemicals. Mol Endocrinol 2006;20:475-82.

25. Rehman S, Usman Z, Rehman S, et al. Endocrine disrupting chemicals and impact on male reproductive health. Transl Androl Urol 2018;7:490-503.

26. Kubincová P, Sychrová E, Raška J, et al. Polycyclic Aromatic Hydrocarbons and Endocrine Disruption: Role of Testicular Gap Junctional Intercellular Communication and Connexins. Toxicol Sci 2019;169:70-83.

27. Jacobsen NR, Clausen PA. Carbon black nanoparticles and other problematic constituents of black ink and their potential to harm tattooed humans. Curr Probl Dermatol 2015;48:170-5.

28. Katsikantami I, Sifakis S, Tzatzarakis MN, et al. A global assessment of phthalates burden and related links to health effects. Environ Int 2016;97:212-36.

29. Wang YX, Zeng Q, Sun Y, et al. Semen phthalate metabolites, semen quality parameters and serum 
reproductive hormones: A cross-sectional study in China. Environ Pollut 2016;211:173-82.

30. Lyche JL, Gutleb AC, Bergman A, et al. Reproductive and developmental toxicity of phthalates. J Toxicol Environ Health B Crit Rev 2009;12:225-49.

31. Kay VR, Bloom MS, Foster WG. Reproductive and developmental effects of phthalate diesters in males. Crit Rev Toxicol 2014;44:467-98.

32. Chauvigné F, Plummer S, Lesné L, et al. Mono-(2ethylhexyl) phthalate directly alters the expression of Leydig cell genes and CYP17 lyase activity in cultured rat fetal testis. PLoS One 2011;6:e27172.

33. Lin H, Ge RS, Chen GR, et al. Involvement of testicular growth factors in fetal Leydig cell aggregation after exposure to phthalate in utero. Proc Natl Acad Sci USA 2008;105:7218-22.

34. Lin YC, Yao PL, Richburg JH. FasL gene-deficient mice display a limited disruption in spermatogenesis and inhibition of mono-(2-ethylhexyl) phthalate-induced germ cell apoptosis. Toxicol Sci 2010;114:335-45.

35. Zhao Y, Ao H, Chen L, et al. Mono-(2-ethylhexyl) phthalate affects the steroidogenesis in rat Leydig cells through provoking ROS perturbation. Toxicol In Vitro 2012;26:950-5.

36. Cai H, Zheng W, Zheng $\mathrm{P}$, et al. Human urinary/seminal phthalates or their metabolite levels and semen quality: A meta-analysis. Environ Res 2015;142:486-94.

37. Gould JC, Leonard LS, Maness SC, et al. Bisphenol A interacts with the estrogen receptor alpha in a distinct manner from estradiol. Mol Cell Endocrinol 1998;142:203-14.

38. Dobrzyńska MM, Radzikowska J. Genotoxicity and reproductive toxicity of bisphenol $\mathrm{A}$ and $\mathrm{X}$-ray/bisphenol A combination in male mice. Drug Chem Toxicol 2013;36:19-26.

39. Tainaka H, Takahashi H, Umezawa M, et al. Evaluation of the testicular toxicity of prenatal exposure to bisphenol A based on microarray analysis combined with $\mathrm{MeSH}$ annotation. J Toxicol Sci 2012;37:539-48.

40. Tiwari D, Vanage G. Mutagenic effect of Bisphenol A on adult rat male germ cells and their fertility. Reprod Toxicol 2013;40:60-8.

41. Salian S, Doshi T, Vanage G. Neonatal exposure of male rats to Bisphenol A impairs fertility and expression of sertoli cell junctional proteins in the testis. Toxicology 2009;265:56-67.

42. Qiu L-L, Wang X, Zhang X, et al. Decreased androgen receptor expression may contribute to spermatogenesis failure in rats exposed to low concentration of bisphenol A. Toxicol Lett 2013;219:116-24.

43. Minamiyama Y, Ichikawa H, Takemura S, et al. Generation of reactive oxygen species in sperms of rats as an earlier marker for evaluating the toxicity of endocrine-disrupting chemicals. Free Radic Res 2010;44:1398-406.

44. Chitra KC, Latchoumycandane C, Mathur PP. Induction of oxidative stress by bisphenol A in the epididymal sperm of rats. Toxicology 2003;185:119-27.

45. Liu C, Duan W, Li R, et al. Exposure to bisphenol A disrupts meiotic progression during spermatogenesis in adult rats through estrogen-like activity. Cell Death Dis 2013;4:e676.

46. Rashid H, Ahmad F, Rahman S, et al. Iron deficiency augments bisphenol A-induced oxidative stress in rats. Toxicology 2009;256:7-12.

47. Wu HJ, Liu C, Duan WX, et al. Melatonin ameliorates bisphenol A-induced DNA damage in the germ cells of adult male rats. Mutat Res 2013;752:57-67.

48. Mínguez-Alarcón L, Hauser R, Gaskins AJ. Effects of bisphenol A on male and couple reproductive health: a review. Fertil Steril 2016;106:864-70.

49. Li DK, Zhou Z, Miao M, et al. Urine bisphenol-A (BPA) level in relation to semen quality. Fertil Steril 2011;95:625630.e1-4.

50. Lassen TH, Frederiksen H, Jensen TK, et al. Urinary bisphenol A levels in young men: association with reproductive hormones and semen quality. Environ Health Perspect 2014;122:478-84.

51. Meeker JD, Yang T, Ye X, et al. Urinary concentrations of parabens and serum hormone levels, semen quality parameters, and sperm DNA damage. Environ Health Perspect 2011;119:252-7.

52. Dodge LE, Williams PL, Williams MA, et al. Paternal Urinary Concentrations of Parabens and Other Phenols in Relation to Reproductive Outcomes among Couples from a Fertility Clinic. Environ Health Perspect 2015;123:665-71.

53. Buck Louis GM, Sundaram R, Sweeney AM, et al. Urinary bisphenol A, phthalates, and couple fecundity: the Longitudinal Investigation of Fertility and the Environment (LIFE) Study. Fertil Steril 2014;101:1359-66.

54. Rana SVS. Perspectives in endocrine toxicity of heavy metals--a review. Biol Trace Elem Res 2014;160:1-14.

55. Ramos-Treviño J, Bassol-Mayagoitia S, Hernández-Ibarra JA, et al. Toxic Effect of Cadmium, Lead, and Arsenic on the Sertoli Cell: Mechanisms of Damage Involved. DNA Cell Biol 2018;37:600-8. 
56. de Angelis C, Galdiero M, Pivonello C, et al. The environment and male reproduction: The effect of cadmium exposure on reproductive function and its implication in fertility. Reprod Toxicol 2017;73:105-27.

57. Hernández-Ochoa I, García-Vargas G, López-Carrillo $\mathrm{L}$, et al. Low lead environmental exposure alters semen quality and sperm chromatin condensation in northern Mexico. Reprod Toxicol 2005;20:221-8.

58. Adhikari N, Sinha N, Saxena DK. Effect of lead on Sertoligerm cell coculture of rat. Toxicol Lett 2000;116:45-9.

59. Mahmoud A, Kiss P, Vanhoorne M, et al. Is inhibin B involved in the toxic effect of lead on male reproduction? Int J Androl 2005;28:150-5.

60. Henriques MC, Loureiro S, Fardilha M, et al. Exposure to mercury and human reproductive health: A systematic review. Reprod Toxicol 2019;85:93-103.

61. Guvvala PR, Sellappan S, Parameswaraiah RJ. Impact of $\operatorname{arsenic}(\mathrm{V})$ on testicular oxidative stress and sperm functional attributes in Swiss albino mice. Environ Sci Pollut Res Int 2016;23:18200-10.

62. Kim YJ, Kim JM. Arsenic Toxicity in Male Reproduction and Development. Dev Reprod 2015;19:167-80.

63. Boujbiha MA, Hamden K, Guermazi F, et al. Testicular toxicity in mercuric chloride treated rats: association with oxidative stress. Reprod Toxicol 2009;28:81-9.

64. Chang SI, Jin B, Youn P, et al. Arsenic-induced toxicity and the protective role of ascorbic acid in mouse testis. Toxicol Appl Pharmacol 2007;218:196-203.

65. Kalender S, Uzun FG, Demir F, et al. Mercuric chlorideinduced testicular toxicity in rats and the protective role of sodium selenite and vitamin E. Food Chem Toxicol 2013;55:456-62.

66. Rao MV, Sharma PS. Protective effect of vitamin $\mathrm{E}$ against mercuric chloride reproductive toxicity in male mice. Reprod Toxicol 2001;15:705-12.

67. Balise VD, Meng CX, Cornelius-Green JN, et al. Systematic review of the association between oil and natural gas extraction processes and human reproduction. Fertil Steril 2016;106:795-819.

68. De Felice F, Marchetti C, Marampon F, et al. Radiation effects on male fertility. Andrology 2019;7:2-7.

69. Maartens PJ, Flint M, du Plessis S. Ionizing Radiation. In: Male Infertility: A Complete Guide to Lifestyle and Environmental Factors. New York, NY: Springer, 2014:211-23.

70. Birioukov A, Meurer M, Peter RU, et al. Male Reproductive System in Patients Exposed to Ionizing Irradiation in the Chernobyl Accident. Archives of
Andrology 1993;30:99-104.

71. Wdowiak A, Skrzypek M, Stec M, et al. Effect of ionizing radiation on the male reproductive system. Ann Agric Environ Med 2019;26:210-6.

72. Adams JA, Galloway TS, Mondal D, et al. Effect of mobile telephones on sperm quality: a systematic review and meta-analysis. Environ Int 2014;70:106-12.

73. Avendaño C, Mata A, Sanchez Sarmiento CA, et al. Use of laptop computers connected to internet through Wi-Fi decreases human sperm motility and increases sperm DNA fragmentation. Fertil Steril 2012;97:39-45.e2.

74. Kesari KK, Agarwal A, Henkel R. Radiations and male fertility. Reprod Biol Endocrinol 2018;16:118.

75. Sheynkin Y, Jung M, Yoo P, et al. Increase in scrotal temperature in laptop computer users. Hum Reprod 2005;20:452-5.

76. Kamali K, Atarod M, Sarhadi S, et al. Effects of electromagnetic waves emitted from $3 \mathrm{G}+$ wi-fi modems on human semen analysis. Urologia 2017;84:209-14.

77. Cosselman KE, Navas-Acien A, Kaufman JD.

Environmental factors in cardiovascular disease. Nat Rev Cardiol 2015;12:627-42.

78. Lemjabbar-Alaoui H, Hassan OU, Yang YW, et al. Lung cancer: Biology and treatment options. Biochim Biophys Acta 2015;1856:189-210.

79. Vecoli C, Montano L, Andreassi MG. Environmental pollutants: genetic damage and epigenetic changes in male germ cells. Environ Sci Pollut Res Int 2016;23:23339-48.

80. Loomis D, Grosse Y, Lauby-Secretan B, et al. The carcinogenicity of outdoor air pollution. Lancet Oncol 2013;14:1262-3.

81. Jurewicz J, Dziewirska E, Radwan M, et al. Air pollution from natural and anthropic sources and male fertility. Reprod Biol Endocrinol 2018;16:109.

82. Lafuente R, García-Blàquez $\mathrm{N}$, Jacquemin $\mathrm{B}$, et al. Outdoor air pollution and sperm quality. Fertil Steril 2016;106:880-96.

83. Deng Z, Chen F, Zhang M, et al. Association between air pollution and sperm quality: A systematic review and meta-analysis. Environ Pollut 2016;208:663-9.

84. Zhang HT, Zhang Z, Cao J, et al. Ambient ozone pollution is associated with decreased semen quality: longitudinal analysis of 8945 semen samples from 2015 to 2018 and during pollution-control period in Beijing, China. Asian J Androl 2019;21:501-7.

85. Zhang J, Cai Z, Yang B, et al. Association between outdoor air pollution and semen quality: Protocol for an updated systematic review and meta-analysis. Medicine (Baltimore) 
2019;98:e15730.

86. Swami CG, Ramanathan J, Charan Jeganath C. Noise exposure effect on testicular histology, morphology and on male steroidogenic hormone. Malays J Med Sci 2007;14:28-35.

87. Min KB, Min JY. Exposure to environmental noise and risk for male infertility: A population-based cohort study. Environ Pollut 2017;226:118-24.

88. Dzhambov AM. Workplace noise exposure and serum testosterone in men enrolled in the 1999-2004 National Health and Nutrition Examination Survey. Arh Hig Rada Toksikol 2016;67:247-58.

89. Mieusset R, Bujan L. Testicular heating and its possible contributions to male infertility: a review. Int J Androl 1995;18:169-84.

90. Rao M, Zhao XL, Yang J, et al. Effect of transient scrotal hyperthermia on sperm parameters, seminal plasma biochemical markers, and oxidative stress in men. Asian J Androl 2015;17:668-75.

91. Ahmad G, Moinard N, Esquerré-Lamare C, et al. Mild induced testicular and epididymal hyperthermia alters sperm chromatin integrity in men. Fertil Steril 2012;97:546-53.

92. Rao M, Xia W, Yang J, et al. Transient scrotal hyperthermia affects human sperm DNA integrity, sperm apoptosis, and sperm protein expression. Andrology 2016;4:1054-63.

93. Mieusset R, Bengoudifa B, Bujan L. Effect of posture and clothing on scrotal temperature in fertile men. J Androl 2007;28:170-5.

94. Bonde JP. Semen quality in welders exposed to radiant heat. Br J Ind Med 1992;49:5-10.

95. Bujan L, Daudin M, Charlet JP, et al. Increase in scrotal temperature in car drivers. Hum Reprod 2000;15:1355-7.

96. Jockenhövel F, Gräwe A, Nieschlag E. A portable digital data recorder for long-term monitoring of scrotal temperatures. Fertil Steril 1990;54:694-700.

97. Jung A, Leonhardt F, Schill W-B, et al. Influence of the type of undertrousers and physical activity on scrotal temperature. Hum Reprod 2005;20:1022-7.

98. Panara K, Masterson JM, Savio LF, et al. Adverse Effects of Common Sports and Recreational Activities on Male Reproduction. Eur Urol Focus 2019;5:1146-51.

99. Nassan FL, Jensen TK, Priskorn L, et al. Association of Dietary Patterns with Testicular Function in Young Danish Men. JAMA Netw Open 2020;3:e1921610.

100.Håkonsen LB, Thulstrup AM, Aggerholm AS, et al. Does weight loss improve semen quality and reproductive hormones? Results from a cohort of severely obese men. Reprod Health 2011;8:24.

101. Eisenberg ML, Kim S, Chen Z, et al. The relationship between male BMI and waist circumference on semen quality: data from the LIFE study. Hum Reprod 2014;29:193-200.

102. Lee Y, Dang JT, Switzer N, et al. Impact of bariatric surgery on male sex hormones and sperm quality: a systematic review and meta-analysis. Obes Surg 2019;29:334-46.

103. Jóźków P, Rossato M. The Impact of Intense Exercise on Semen Quality. Am J Mens Health 2017;11:654-62.

104. Ricci E, Viganò P, Cipriani S, et al. Coffee and caffeine intake and male infertility: a systematic review. Nutr J 2017;16:37.

105.Li Y, Lin H, Li Y, et al. Association between socio-psychobehavioral factors and male semen quality: systematic review and meta-analyses. Fertil Steril 2011;95:116-23.

106. Karmon AE, Toth TL, Chiu YH, et al. Male caffeine and alcohol intake in relation to semen parameters and in vitro fertilization outcomes among fertility patients. Andrology 2017;5:354-61.

107. Kovac JR, Khanna A, Lipshultz LI. The effects of cigarette smoking on male fertility. Postgrad Med 2015;127:338-41.

108. Bundhun PK, Janoo G, Bhurtu A, et al. Tobacco smoking and semen quality in infertile males: a systematic review and meta-analysis. BMC Public Health 2019;19:36.

109. Sharma R, Harlev A, Agarwal A, et al. Cigarette Smoking and Semen Quality: A New Meta-analysis Examining the Effect of the 2010 World Health Organization Laboratory Methods for the Examination of Human Semen. Eur Urol 2016;70:635-45.

110. Talhout R, Schulz T, Florek E, et al. Hazardous compounds in tobacco smoke. Int J Environ Res Public Health 2011;8:613-28.

111.El Golli N, Rahali D, Jrad-Lamine A, et al. Impact of electronic-cigarette refill liquid on rat testis. Toxicol Mech Methods 2016;26:427-34.

112.Substance Abuse and Mental Health Services Administration. Key substance use and mental health indicators in the United States: Results from the 2018 National Survey on Drug Use and Health [Internet]. Rockville, MD: Center for Behavioral Health Statistics and Quality, Substance Abuse and Mental Health Services Administration; 2019. Available online: https://www. samhsa.gov/data

113. Muthusami KR, Chinnaswamy P. Effect of chronic alcoholism on male fertility hormones and semen quality. 
Fertil Steril 2005;84:919-24.

114. Sengupta SN, Ray R, Shetty KT, et al. Pituitary gonadal functioning in male alcoholics in an Indian psychiatric hospital. Alcohol Alcohol 1991;26:47-51.

115. Heinz A, Rommelspacher H, Gräf KJ, et al. Hypothalamicpituitary-gonadal axis, prolactin, and cortisol in alcoholics during withdrawal and after three weeks of abstinence: comparison with healthy control subjects. Psychiatry Res 1995;56:81-95.

116. Lindholm J, Fabricius-Bjerre N, Bahnsen M, et al. Pituitary-testicular function in patients with chronic alcoholism. Eur J Clin Invest 1978;8:269-72.

117. Van Thiel DH, Gavaler JS, Rosenblum E, et al. Effects of ethanol on endocrine cells: testicular effects. Ann N Y Acad Sci 1987;492:287-302.

118. Gümüş B, Yiğitoğlu MR, Lekili M, et al. Effect of longterm alcohol abuse on male sexual function and serum gonadal hormone levels. Int Urol Nephrol 1998;30:755-9.

119.du Plessis SS, Agarwal A, Syriac A. Marijuana, phytocannabinoids, the endocannabinoid system, and male fertility. J Assist Reprod Genet 2015;32:1575-88.

120. Agirregoitia E, Carracedo A, Subirán N, et al. The CB(2) cannabinoid receptor regulates human sperm cell motility. Fertil Steril 2010;93:1378-87.

121.Amoako AA, Marczylo TH, Marczylo EL, et al. Anandamide modulates human sperm motility: implications for men with asthenozoospermia and oligoasthenoteratozoospermia. Hum Reprod 2013;28:2058-66.

122. Rossato M, Ion Popa F, Ferigo M, et al. Human sperm express cannabinoid receptor $\mathrm{Cb} 1$, the activation of which inhibits motility, acrosome reaction, and mitochondrial function. J Clin Endocrinol Metab 2005;90:984-91.

123. Sagoe D, Molde H, Andreassen CS, et al. The global epidemiology of anabolic-androgenic steroid use: a metaanalysis and meta-regression analysis. Ann Epidemiol 2014;24:383-98.

124. Tatem AJ, Beilan J, Kovac JR,et al. Management of Anabolic Steroid-Induced Infertility: Novel Strategies for Fertility Maintenance and Recovery. World J Mens Health 2020;38:141-50.

125.Avant RA, Charchenko CM, Alom M, et al. Medication patterns and fertility rates in a cohort of anabolic steroid users. Transl Androl Urol 2018;7:S198-204.

126.McBride JA, Coward RM. Recovery of spermatogenesis following testosterone replacement therapy or anabolicandrogenic steroid use. Asian J Androl 2016;18:373-80.

127.Drobnis EZ, Nangia AK. Male Reproductive Functions
Disrupted by Pharmacological Agents. In: Impacts of Medications on Male Fertility. Cham: Springer, 2017.

128. Brezina PR, Yunus FN, Zhao Y. Effects of pharmaceutical medications on male fertility. J Reprod Infertil 2012;13:3-11.

129. Beeder LA, Samplaski MK. Effect of antidepressant medications on semen parameters and male fertility. Int J Urol 2020;27:39-46.

130. Semet M, Paci M, Saïas-Magnan J, et al. The impact of drugs on male fertility: a review. Andrology 2017;5:640-63.

131. Bawor M, Bami H, Dennis BB, et al. Testosterone suppression in opioid users: a systematic review and metaanalysis. Drug Alcohol Depend 2015;149:1-9.

132. Farag AGA, Basha MA, Amin SA, et al. Tramadol (opioid) abuse is associated with a dose- and time-dependent poor sperm quality and hyperprolactinaemia in young men. Andrologia 2018;50:e13026.

133. Safarinejad MR, Asgari SA, Farshi A, et al. The effects of opiate consumption on serum reproductive hormone levels, sperm parameters, seminal plasma antioxidant capacity and sperm DNA integrity. Reprod Toxicol 2013;36:18-23.

134. Agirregoitia E, Valdivia A, Carracedo A, et al. Expression and localization of delta-, kappa-, and mu-opioid receptors in human spermatozoa and implications for sperm motility. J Clin Endocrinol Metab 2006;91:4969-75.

135. Nudell DM, Monoski MM, Lipshultz LI. Common medications and drugs: how they affect male fertility. Urol Clin North Am 2002;29:965-73.

136. Nordkap L, Joensen UN, Blomberg Jensen M, et al. Regional differences and temporal trends in male reproductive health disorders: semen quality may be a sensitive marker of environmental exposures. Mol Cell Endocrinol 2012;355:221-30.

137. Wang S, Romanak KA, Stubbings WA, et al. Silicone wristbands integrate dermal and inhalation exposures to semi-volatile organic compounds (SVOCs). Environ Int 2019;132:105104.

138. Hendryx M, Wang S, Romanak KA, et al. Personal exposure to polycyclic aromatic hydrocarbons in Appalachian mining communities. Environ Pollut 2020;257:113501.

139. Priskorn L, Nordkap L, Bang AK, et al. Average sperm count remains unchanged despite reduction in maternal smoking: results from a large cross-sectional study with annual investigations over 21 years. Hum Reprod 2018;33:998-1008.

140.Prentki Santos E, López-Costa S, Chenlo P, et al. Impact 
of spontaneous smoking cessation on sperm quality: case report. Andrologia 2011;43:431-5.

141.Zorgniotti AW, Sealfon AI, Toth A. Chronic scrotal hypothermia as a treatment for poor semen quality. Lancet 1980;1:904-6.

142.Jung A, Eberl M, Schill WB. Improvement of semen quality by nocturnal scrotal cooling and moderate behavioural change to reduce genital heat stress in men with oligoasthenoteratozoospermia. Reproduction 2001;121:595-603.

143. Nikolopoulos I, Osman W, Haoula Z, et al. Scrotal cooling and its benefits to male fertility: a systematic review. J Obstet Gynaecol 2013;33:338-42.

144. Said RS, Mohamed HA, Kamal MM. Coenzyme Q10 mitigates ionizing radiation-induced testicular damage in rats through inhibition of oxidative stress and mitochondria-mediated apoptotic cell death. Toxicol Appl

Cite this article as: Krzastek SC, Farhi J, Gray M, Smith RP. Impact of environmental toxin exposure on male fertility potential. Transl Androl Urol 2020;9(6):2797-2813. doi: 10.21037/tau-20-685
Pharmacol 2019;383:114780.

145.El-Mesallamy HO, Gawish RA, Sallam AAM, et al. Ferulic acid protects against radiation-induced testicular damage in male rats: impact on SIRT1 and PARP1. Environ Sci Pollut Res Int 2018;25:6218-27.

146. Asadi N, Bahmani M, Kheradmand A, et al. The Impact of Oxidative Stress on Testicular Function and the Role of Antioxidants in Improving it: A Review. J Clin Diagn Res 2017;11:IE01-5.

147. Smits RM, Mackenzie-Proctor R, Yazdani A, et al. Antioxidants for male subfertility. Cochrane Database Syst Rev 2019 14;3:CD007411.

148. Ring JD, Lwin AA, Köhler TS. Current medical management of endocrine-related male infertility. Asian J Androl 2016;18:357-63.

149. Ramasamy R, Stahl PJ, Schlegel PN. Medical therapy for spermatogenic failure. Asian J Androl 2012;14:57-60. 